\title{
LEE-LI YANG: A RADICALIZAÇÃO DO FINGIMENTO POÉTICO
}

Luciana Brandão Leal ${ }^{1}$

\begin{abstract}
Resumo: Este artigo apresenta uma leitura de poesias escritas por Lee-Li Yang, heterônimo feminino do poeta moçambicano Virgílio de Lemos. Para tanto, consideram-se os aspectos semióticos que caracterizam a dicção feminina, bem como o erotismo e a melancolia presentes nos poemas de Lee-Li Yang. A partir da leitura dos poemas selecionados, evidencia-se que há, realmente, características literárias que são predominantemente do universo feminino. Pretende-se, também, avaliar em que medida o poeta Virgílio de Lemos simula, na escrita de Lee-Li Yang, a "experiência corporal, interior, social e cultural” (JORGE, 1995, p. 23) inerente ao universo das mulheres.
\end{abstract}

Palavras-Chave: Erotismo, Heteronímia, Lee-Li Yang, Melancolia, Virgilio de Lemos

Abstract: This article presents a reading of poems written by Lee-Li Yang, female heteronym of the Mozambican poet Virgílio de Lemos. Therefore, we consider the semiotic aspects that characterize female diction, as well as the eroticism and melancholy present in Lee-Li Yang's poems. From the reading of the selected poems, it is evident that there are, indeed, literary features that are predominantly of the feminine universe. The aim is also to evaluate the extent to which Lemos poet Virgil simulates in Lee-Li Yang's writing, an "corporal, inward, social and cultural experience" (JORGE, 1995, p.23) inherent in the women universe.

Kewords: Eroticism, Heteronym, Lee-Li Yang, Melancholy Virgilio de Lemos

Para uma reflexão sobre a escrita feminina, retomam-se, aqui, alguns conceitos discutidos por Lúcia Castelo Branco (1991), que afirma que a "literatura feminina" não pode ser entendida exclusivamente como sinônimo de literatura produzida por mulheres, como se esse tipo de texto só pudesse ser escrito por mulheres. Por outro lado, para justificar que não existem dois polos distintos definidos pelo gênero de quem escreve, Julia Kristeva afirma que tanto Joyce quanto Proust são autores que manifestam uma "écriture féminine". Lúcia Castelo Branco, inspirada pelas reflexões de Julia Kristeva, considera, ainda, que os textos de autoria feminina se diferenciam dos demais porque possuem um “tom, uma dicção, um ritmo, uma respiração próprios” (CASTELO BRANCO, 1991, p. 13). Observando-se os elementos semióticos predominantes na escrita de mulheres, constata-se que a feminilidade é adquirida; ou seja: não está essencialmente determinada pelo corpo de uma mulher, mas está, de alguma forma, relacionada à mulher; mesmo quando ela é praticada por homens, o que se tem é um olhar característico do universo feminino.

$\mathrm{Na}$ história da literatura portuguesa, as cantigas medievais de amigo apresentam vozes femininas cujos versos são tecidos como os fios de Penélope, esposa de Ulisses que, durante a ausência do marido, permanece fiel e devota. São mulheres que cantam enquanto tecem ou trabalham, sempre à espera do regresso do homem amado, falando à mãe, à amiga, à irmã ou mesmo à natureza. Prevalece o tema da relação amorosa e da mulher se queixa ora por não ter seu amor correspondido, ora pela separação de seu amado, que acontece por diversos motivos, como as guerras ou as expedições 1 Professora Adjunta na Universidade Federal de Viçosa, atuando no Campus Florestal. Doutora em Letras - Literatura de Língua Portuguesa, pela Pontifícia Universidade Católica de Minas Gerais (2018). Atuou como pesquisadora visitante na Universidade de Lisboa (2017). 
marítimas.

Vejamos um exemplo:

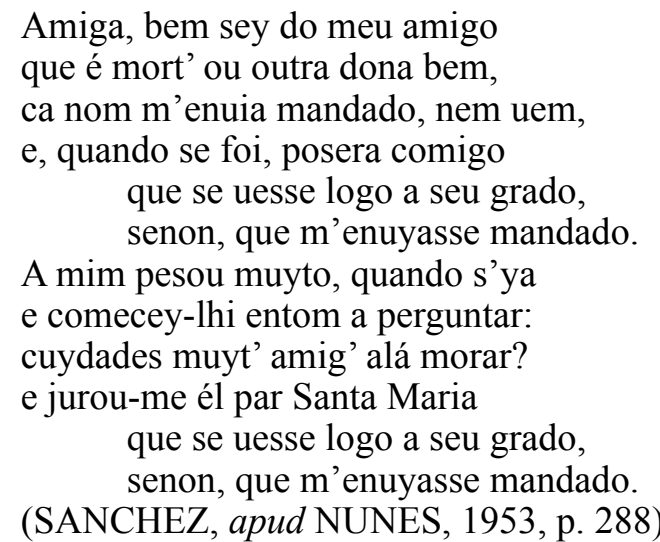

Nesses versos escritos por Sancho Sanchez, a voz feminina se queixa pela falta do seu amigo, que pode estar morto ou ter se apaixonado por outra mulher, uma vez que não lhe envia recado algum, nem retorna "de bom grado", conforme prometido. A aparente simplicidade semântica ocorre, sobretudo, pela repetição do pensamento com poucas variações formais, além da reiteração de verbos e do uso de sinônimos. O ritmo e a musicalidade são dados pelos paralelismos e pela repetição dos pares de versos, como em um refrão. O peso do refrão aparece como determinante da cantiga citada, servindo de mote para o poema. É certo que a música e a oralidade são fundamentais para a construção das trovas, que privilegiam o som, ao invés do registro escrito.

O tom das cantigas de amigo se aproxima do confessional, que é próprio do universo feminino, uma vez que as mulheres, historicamente confinadas ao âmbito doméstico, "teriam encontrado nesse tipo de escrita o veículo ideal para expressão de sua vida íntima, seus desejos, suas fantasias" (CASTELO BRANCO, 1991, p. 30).

A natureza também pode figurar como confidente e, geralmente, está em sintonia com o estado de espírito do eu lírico. As ondas ora representam a esperança e a possibilidade de trazer notícias do amigo: "Ai ondas que eu vin veer / se me saberedes dizer / por que tarda meu amigo?" (CODAX, apud NUNES, 1953, p. 356); ora surgem como desconsolo pela morte solitária: “[E] nem ey barqueyro [e] nem sey remar / e morrerey, fremosa, no alto mar. / eu atendend' o meu amigo!/ eu atendend' o meu amigo!" (MEENDINHO, apud VIEIRA, 1987, p. 115).

Nas cantigas de amigo, o poeta cria um eu lírico feminino que expressa a disparidade dos sentimentos amorosos. $\mathrm{O}$ estado de alma oscila entre a expectativa pela concretização do amor e a frustração causada pela falta do amigo/amado. Em algumas cantigas trovadorescas, o erotismo surge como mote e viés dos poemas. Enquanto as cantigas de amor encenam o desejo por uma senhora inacessível, em um cenário platônico, nas cantigas de amigo existe a possibilidade do reencontro. 
Prevalecem verbos que expressam um futuro incerto, o que reforça o tom condicional. Tomemos como exemplo este trecho de uma cantiga de Johan de Requeixo: "A Far um dia irei, madre, se vos prouguer / rogar se verria meu amigo, que mi ben quer / e direi lh' eu enton / a coita do meu coraçon" (REQUEIXO apud NUNES, 1953, p. 212). Consta-se, nesses versos, a possibilidade do encontro amoroso, apesar dos obstáculos que se interpõem entre os amantes. A expressão "um dia" reforça o tom de indeterminação, porque o encontro só acontecerá com o consentimento da mãe, a quem o eu lírico suplica que a autorize rever seu amigo.

Em outro poema, intitulado "Fui eu, madre, lavar meus cabelos", de Johan Soarez Coelho, o potencial erótico é trazido pelas metáforas e pela carga simbólica evocada pelos versos. A donzela conta à mãe que foi lavar seus cabelos na fonte e se encantou com o que viu, porque, ao se observar refletida nas águas, achou-se bela. Em seguida, relata a chegada do amigo, "senhor dos seus cabelos", que lhe agradou com palavras gentis:

Fui eu, madre, lavar meus cabelos a la fonte e paguei-m'eu d'elos e de mí, louçana.

Fui eu, madre, lavar mias garcetas

a la fonte e paguei-m'eu delas e de mí, louçana

A la fonte e paguei-m'eu deles, alo achei, madr', o senhor deles e de mí, louçana.

Ante que me eu d'alí partisse, fui pagada do que me el disse e de mí, louçana. (COELHO apud NUNES, 1953, p. 356)

O apelo erótico está no ato de lavar os cabelos, e na menção a uma fonte, local de renovação e fertilidade. Como esclarece Huizinga (2010), era comum, no período medieval, a representação simbólica de questões sexuais ou mesmo a descrição do ato sexual através de imagens de atividades sociais. Lavar os cabelos ou as vestes, como no exemplo citado, tem conotação erótica, porque à água e ao movimento dos cabelos são atribuídos significados figurativos que evocam sensualidade. A penúltima estrofe sugere ao leitor um possível encontro amoroso, já que a moça se refere ao amigo/ amado como “o senhor de seus cabelos”, metonímia de seu próprio corpo: “alo achei, madr', o senhor deles / e de mí, louçana".

Virgílio de Lemos, ao criar seu heterônimo feminino, Lee-Li Yang, retoma algumas características das cantigas de amigo: em ambos os casos, o poeta simula vozes de mulheres que se queixam da ausência do amigo/amado e expressam todo o erotismo e a sensualidade da comunhão amorosa, vivenciada ou apenas pretendida.

Dialogando com cantigas medievais de amigo e com as "Cartas Portuguesas", os poemas 
de Lee-Li Yang têm caráter confessional, partilham o tom sensual e melancólico, provocado pela ausência do amado, motivo da escrita e da paixão. Produzidas no século XII, as "Cartas Portuguesas", de Sóror Mariana Alcoforado, também ecoam na lírica de Lee-Li Yang. As cinco missivas escritas pela freira portuguesa, publicadas, em 1669, sob o título "Lettres Portugaises", tornaram-se um clássico da literatura universal. Mariana Alcoforado, mesmo sem vocação religiosa, fora levada para um convento aos onze anos. Suas cartas de amor foram escritas para Noël Bouton de Chamilly, oficial francês que lutou em solo português durante a Guerra da Restauração. Mariana vivia enclausurada, à espera de notícias de seu amado. As cartas têm a mesma tônica: tecidas pela melancolia de uma mulher que experimenta a paixão e o abandono. No fragmento a seguir, transcrito da primeira carta da freira Sóror Mariana Alcoforado, lê-se:

[...] Considera, meu amor, a que ponto chegou a tua imprevidência. Desgraçado!, foste enganado e enganaste-me com falsas esperanças. Uma paixão de que esperaste tanto prazer não é agora mais que desespero mortal, só comparável à crueldade da ausência que o causa $[\ldots]$

(ALCOFORADO, 2013, p. 10)

Assim como nas cantigas medievais e nas cartas de Sóror Mariana Alcoforado, o tom apelativo e o sofrimento pela ausência se repetem em vários poemas do heterônimo feminino de Virgílio de Lemos: "é sempre a tua ausência o que / me empolga e / me leva de joelhos a pedir-te / que voltes / do mar das ilhas / do desejo / primavera tropical e / lívida nas elipses / da paixão".

No caso de Lee-Li Yang, o que se vê, entretanto, é a radicalização do fingimento poético: Virgílio de Lemos atribui a ela a autoria dos poemas. Quando simula a voz e a autoria de Lee-Li Yang, Virgílio de Lemos prima por reforçar as características que são próprias do universo feminino, porque, como escreve Ana Mafalda Leite:

Ser mulher é ser diferente, e semelhante diferença estabelece a relação da estranheza; entre os mitos de bruxa, virgem, demónio ou anjo, que são ambígua, irónica, e textualmente des(construídos) pelo discurso da poeta, nota-se, no entanto, a figuração propositada de um outro [...] (LEITE, 2006, p. 389).

Lee-Li Yang representa a condição de mulher independente contrapondo-se aos rígidos parâmetros da realidade colonial moçambicana, marcada pela opressão sexual e social das mulheres e suas lutas de libertação. É uma mulher independente, viajada e culta, que não se curvou ao domínio dos homens; ao contrário, assumiu uma postura transgressora e ousada frente aos moldes machistas de sua época. No emblemático poema “O Mar de mim”, Lee-Li Yang reforça sua postura subversiva, contradizendo várias imposições sociais que pesam sobre as mulheres, silenciando-as, mutilando-as. A insubmissão parte das negações de condutas pré-estabelecidas, o primeiro verso de cada estrofe 
ratifica que "A alma da mulher não é... silêncio / cicatriz sem voz / vergonha de ser / desfocado rosto m'siro". Vejamos:

$$
\begin{aligned}
& \text { O Mar de mim } \\
& \text { 1. } \\
& \text { A alma } \\
& \text { da mulher não é } \\
& \text { silêncio } \\
& \text { insustentável voz } \\
& \text { de um véu } \\
& \text { redutor uma oração } \\
& \text { que aconteceu e } \\
& \text { desteceu. Já não é. }
\end{aligned}
$$

\section{2.}

A alma

da mulher não é

bem a luz

de um mutilado ser

em ti oculto

cicatriz sem voz

meu desviver.

3.

A alma

da mulher não é

bem o Eu

não ter

vergonha de ser

EU

estética visão

do insubmisso fundo

de mim.

4.

A alma

da mulher não é

bem kapulana sari e

hijab

desfocado rosto m'siro

cor e perfume

do meu gesto

mas vertigem entre

o pleno e

o vazio

o mar

em mim.

(YANG in LEMOS, 2009, p. 145-146)

Mesmo com todo o rigor e a inflexibilidade do sistema patriarcal, Lee-Li Yang faz ecoar sua atitude reivindicativa e crítica em relação ao pensamento opressor. Nos versos de "Submersa voz de mim", o eu lírico incorpora a subversão (ao dar vazão à submersa voz feminina) e reivindica a 
liberdade do "Amor" por meio da palavra poética:

\author{
Submersa voz de mim \\ Para mim serei \\ Entrelaçados mitos \\ Rituais de reconciliação e \\ Liberdade \\ Na ponte da poesia \\ Inquietação lucidez e \\ Fantasia Amor por \\ Amor.
}

(YANG in LEMOS, 2009, p. 151)

A dicção do poema, - metonímia da lírica de Lee-Li Yang - aproxima-se do que analisa Luíza Neto Jorge sobre a "identidade feminina", na medida em que a sua voz resgata "as suas realizações simbólicas, procurando encontrar uma linguagem própria para as experiências do corpo e da intersubjetividade, deixadas mudas pela cultura dominante" (JORGE, 1995, p. 19).

Virgílio de Lemos define a singularidade poética de Lee-Li Yang, que escreveu cerca de trinta e sete poemas entre 1951 e 1953. Ao falar sobre os traços e peculiaridades desse heterônimo, afirma:

\begin{abstract}
Essa macaísta, no fundo, reivindicava o direito de ser dona exclusiva de seu corpo de mulher, numa sociedade machista, que marginalizava tanto as negras, como as brancas, as chinesas, indianas, as mulatas e as mestiças. Lee-Li Yang metaforiza o corpo do desejo de uma escritura que se faz arma política de libertação feminina. Mulher viajada e com grande cultura, ela não se batia contra os homens; procurava dialogar com eles, mesmo quando denunciava o machismo. Não se restringia a qualquer feminismo de época. Entre sol e sombra, ardor e solidão, buscava a própria voz. O oriente a que recorria era metáfora do Infinito, o outro lado da vida, espaço de liberdade do próprio inconsciente. (LEMOS, 1999, p. 146).
\end{abstract}

Lee-Li Yang escreve poemas que se assemelham a breves cartas de amor, missivas, que possuem grande densidade emocional e um ciclo especialmente marcado pela musicalidade e pelo erotismo. Como se sabe, a carta é um gênero que pressupõe a presença de um interlocutor específico que, no caso das de Lee-Li Yang, é outro heterônimo virgiliano: Duarte Galvão. Virgílio de Lemos esclarece: "Os poemas eram dedicados ao seu amado Duarte Galvão. Eram pequenos poemas ligados por um fio comum, fio de luz, força da paixão de Lee-Li Yang e do Dom Juanismo do seu companheiro" (LEMOS, 1999, p. 146).

A sensualidade erótica é uma característica da lírica de Lee-Li Yang, uma vez que o erotismo do corpo se transfigurava em arma para liberação feminina, desdobrando-se em ritmo e visualidade. Seus poemas simulam movimentos corporificados, na letra, por sons que erotizam ainda mais a escrita desse heterônimo. A dicção dos poemas de Lee-Li Yang reitera o que afirma Jorge (1995) sobre a escrita feminina - escrita do corpo: 
Observamos nestes textos a corporização da ideia de uma escrita feita com o próprio corpo, uma "body writing", como the chamam algumas correntes críticas americanas. Essa escrita tem a ver, por um lado, com uma percepção interior em que o corpo, em vez de ser olhado de fora, é expresso a partir de dentro. (JORGE, 1995, p. 31).

É como se a cadência da poesia aproximasse o corpo desejante da mulher ao de seu amado, em uma dança melancólica, marcada pela cicatriz da falta. Tem-se a procura irremediável pelo outro, a busca por retomar as experiências amorosas vividas que, agora, persistem apenas na memória e no desejo. Esse tom melancólico está estampado no poema "Todo o meu desencanto", onde o eu lírico simula um movimento sensual e triste, como um corpo que suplica, "um caracol de abismos e silêncios". Vejamos:

Todo o meu desencanto
Não atas nem desatas
deixas a coisa tal barca
de papel

a flutuar

De quando em quando

és vendaval

submarino

a ressaca

de teus próprios gritos

na obsessão de mim

Mas nesta viagem salgada

por teu imerso sol

sei que me deixas perdida

entre o querer-me livre e

a deriva

E entre renúncia e feridas

entre a aceitação e

a incerteza

meu corpo de súplicas

é

um caracol de abismos e

silêncio.

(LEMOS, 2009, p. 5-6)

Já no título desse poema, a expressão "todo meu desencanto", determinada pelo pronome possessivo, indica que se trata de uma imersão na subjetividade do eu lírico. O pronome indefinido "todo" marca a totalidade do desencanto causado pelo romance que "não atas nem desatas / deixas a coisa tal barca / de papel / a flutuar". Um barco frágil, de papel, que já não pode mais ser alcançado pela voz poética, porque está ao longe, a flutuar. 
A disposição formal do verso "a flutuar", solto, distante dos demais da mesma estrofe, também adquire novas significações; além do movimento do próprio barco, pode ser interpretado como o movimento do desejo do eu lírico, que flutua em direção às suas memórias e ao reencontro de seu amado, além das palavras e metáforas, que flutuam no texto e propõem significados múltiplos.

Num primeiro momento, existe a pulsão erótica metaforizada pelas palavras "vendaval" e "ressaca", como se, numa primeira acepção, o eu lírico definisse a intensidade da paixão, que se perde como "a ressaca / de teus próprios gritos / na obsessão / de mim”. Assim está o barco, à deriva, em águas que se constituem como espaço privilegiado para a comunhão do desejo. Mais uma vez, a água assume seu potencial erótico; no poema em análise, tem-se uma viagem por águas salgadas, o que reforça o tom melancólico.

Aí, também, se vê o eu lírico que suplica a presença do amado, marcado pelo espaço da separação que se faz “entre renúncias e feridas; entre a aceitação e a incerteza". Águas em movimento, o mar e o poema simbolizam um estado transitório entre as possibilidades ainda incertas, como o coração humano, enquanto lugar das paixões.

No poema "Se partes serei luto", a voz poética expressa como a ausência do amado lhe causa melancolia e dor:

\author{
Se partes serei luto e \\ Sofrimento \\ De joelhos implorarei \\ $O$ poder das bruxas, serei \\ Melancolia \\ Ausência e desprazer [...] \\ (YANG in LEMOS, 2009, p. 159)
}

A incerteza e a frustração são também acentuadas pelos tempos verbais recorrentes nos poemas de Lee-Li Yang. Nos versos "Se partes serei luto e / sofrimento", tem-se uma condicional do tempo e do sentimento do eu lírico que vincula sua dor à ausência do amado.

Também o poema “A solidão do mar" evidencia o tom melancólico, por intermédio de imagens que reiteram a cicatriz da falta, a cárie, a ausência e a solidão. Vejamos:

\author{
Alma \\ na solidão das horas \\ a solidão do meu corpo \\ despossuído e nu \\ solidão da voz \\ de quem ama e \\ se extingue, \\ ausência extrema e \\ violência \\ deserto e solidão do mar. \\ Cordas e cordames
}

Revista Crioula - n 24 - Dissidências de Gênero e Sexualidade nas Literaturas de Língua Portuguesa 


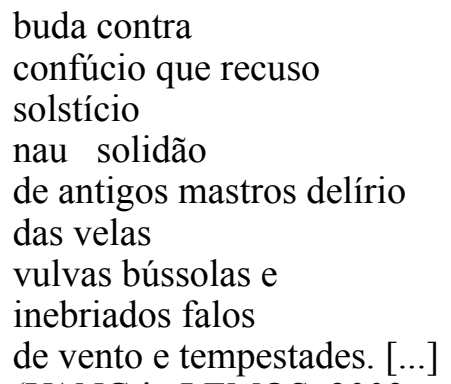

As referências aos corpos masculino e feminino estão em imagens como: "nau", "mastros", "velas", "inebriados falos"; "vulvas" e "bússolas". São sinais anunciadores do desejo, que extrapolam os significados lógicos desses sinais. $\mathrm{O}$ tom de sussurro, dado pelo fonema [S], marca a dicção desse poema. Os silêncios trazem a ideia da falta, a ausência que está tanto no conteúdo quanto na forma apresentada. A solidão sentida pelo eu lírico se desdobra em várias imagens: "o corpo despossuído e nu", "a solidão da voz", "a ausência extrema", "deserto". O desnudamento é um momento decisivo na atividade erótica, uma vez que caracteriza a passagem de um instante de descontinuidade para a predisposição à continuidade, um estado de comunicação entre os corpos, que se revelam parceiros.

$\mathrm{O}$ desnudamento reforça o tom erótico e sugere a desordem que perturba os corpos, em sua individualidade. Pode-se constatar, como explicita Angélica Soares, a propósito de análises de poemas escritos por mulheres, "o território sem fronteiras do desejo, as demarcações do gozo, espaço de manutenção da vida" (SOARES, 2009, p. 28).

O mar, com seu movimento contínuo, confere visualidade e sonoridade aos poemas de Lee-Li Yang e se confunde com os corpos que também se movimentam pelo desejo. Essa metáfora está presente no poema "Acontece que na tua ausência", transcrito a seguir:

\section{ACONTECE QUE NA TUA AUSÊNCIA}

O mar é quem me acalenta

o coração

o mar é quem me canta melodias

num estertor

de orgasmos musicais e cores

voz do amor

de coração a coração.

Acontece que na tua ausência

o mar é quem me suaviza

minhas febres

em cada um dos lados de mim

de ponta a ponta

das minhas ilusões de amor

contra a tempestade e

dentro dela mar

que em mim se vem 
se vai e me acalma

a fome

desta paixão.

(YANG in LEMOS, 2009, p. 141)

Como se vê, a ausência e a solidão alimentam as cartas-poema de Lee-Li Yang endereçadas a Duarte Galvão. Ana Mafalda Leite, quando analisa o processo de escrita desse heterônimo, afirma que se trata de "uma escrita que vive do corpo, e das sensações causadas por ele, provocadas pela ausência do amor, e pela presença crescente de uma força erótica do desejo" (LEITE, 2013, p. 32). No poema lido, a falta do amado não impede que Lee-Li Yang satisfaça seus desejos, porque o mar se transforma em elemento erótico, fonte de prazer.

A escrita do corpo revela a percepção apurada dos diversos sentidos: a visão, o olfato, a audição, o tato, o paladar, mostram-se como antenas igualmente importantes e nítidas para uma captação plural da vida: "Orgasmos musicais e cores / voz do amor”. A linguagem de Lee-Li Yang vale-se de substantivos perfumados, adjetivos palpáveis e verbos audíveis, dando sabor e movimento ao texto. A lírica de Lee-Li canta a vivência e a "satisfação do Desejo insatisfeito" (SOARES, 1999, p. 11), e se apodera do lugar imperativo na realização do erotismo. Para Angélica Soares (1999), a poesia torna-se a própria experiência erótica, uma das características da escrita das mulheres contemporâneas, "da constante tensão entre a consciência literária do erotismo e a consciência erótica do literário; como se, pela textualização do erotismo, melhor se explicitasse o caráter erótico de toda criação" (SOARES, 1999, p. 35).

Reforçando sua personalidade transgressora e libertária, que busca pelo espaço da voz feminina e pela liberdade amorosa, os poemas de Lee-Li Yang, trazem, algumas vezes, erotismo explícito:

\author{
Um coração de gozo! \\ Apalpa minha xaxa, minha noite \\ inquieta surpreende-me arrebata-me \\ liberta-me deste sonho e \\ que eu não seja mais \\ o silêncio do mar. [...] \\ Apalpa minha xaxa, meus \\ seios, lábios, meu tudo \\ em fogo e terás visto \\ quanto perdes \\ deixando-me sonhar \\ com Sófocles devorando \\ minhas incertezas e \\ Epaminondas sem perder \\ o fôlego
}


A linguagem é o espaço da liberdade de sentimentos e sentidos. Revela uma mulher se apodera de seu corpo e de seus desejos. Ao promover o encontro entre o erotismo e a criação literária, o poema enaltece o prazer feminino. Como afirma Ana Mafalda Leite: "a consumação livre desse desejo passional, numa expansão metaforizada pelo Mar e pela assumpção livre do prazer físico que, por vezes, quase narcisicamente, se auto-satisfaz" (LEITE, 2006, p. 384). A escrita do corpo, da autorreferencialidade, reforça o erotismo difuso, escancarando a sensualidade feminina e conferindo uma intensidade singular ao texto de Lee-Li Yang., em cuja poética há a intenção latente de se fazer do gesto da escrita o gesto de libertação da voz feminina. Ao vivenciar e descrever o próprio gozo, a voz lírica intenta combater os mecanismos repressores da subjetividade feminina, ditados pelos padrões convencionais do comportamento social.

Nos versos transcritos acima, tem-se o ritmo frenético do orgasmo, o gozo, que está explícito no título. Nota-se que a falta do amado é retomada pelo sonho, pulsão do desejo erótico. Predomina a linguagem oral, reforçando o apelo e a interlocução, que convoca o outro ao toque, de forma explícita e sensual.

A musicalidade reforça a sensualidade e o erotismo, por meio das metáforas que sugerem os movimentos corporais e o desejo. Nos poemas analisados, percebe-se que o próprio gesto da escrita está em consonância com o universo feminino e, retomando as discussões de Lúcia Castelo Branco (1991), tem o tom, a dicção, o ritmo e a respiração próprios da mulher.

Para Lee-Li Yang, sua interlocutora apaixonada, Duarte Galvão escreve o poema "A solidão se afunda na nudez da alma", cujos versos metapoéticos assim se enunciam:

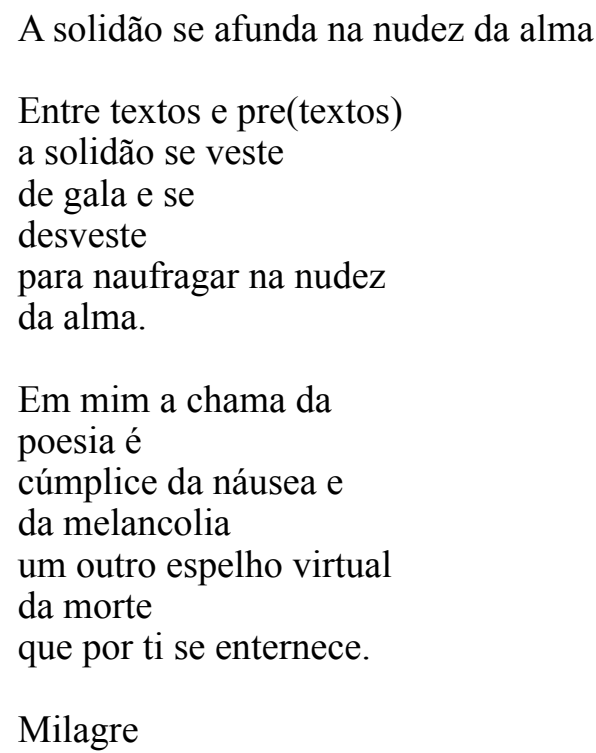

Milagre 
só o perfume

da ficção!

(DUARTE GALVÃO in LEMOS, 2009, p. 190)

Nos versos de Duarte Galvão dirigidos a Lee-Li Yang, prevalece a autorreferencialidade, uma reflexão íntima que se mistura com a análise dos processos de escrita e sua gênese.

Uma mulher apaixonada e melancólica, que através de seus versos eróticos troca missivas com Duarte Galvão, interlocutor constante dos poemas de Lee-Li Yang. Essas são algumas das feições da poética de Virgilio de Lemos em sua heteronímia surpreendente e avassaladora, que arrebata o leitor para intermináveis leituras.

\section{Referências Bibliográficas}

ALCOFORADO, Mariana. Cartas de amor de uma freira portuguesa. [1669] Título original: Lettres Portugaises. Disponível em: <https://www.luso-livros.net/wp-content/uploads/2013/02/Cartas-de-Amor-de-uma-Freira-Portuguesa. pdf $>$. Acesso em: 20 nov. 2017.

BATAILLE, Georges. O erotismo. Tradução de Antônio Carlos Viana. Porto Alegre: L\&PM, 1987.

CASTELO BRANCO, Lúcia. O que é escrita feminina? São Paulo: Brasiliense, 1991.

HANNA, Vera Lúcia. O contraponto poético em “Ó Madalena, ó cabelos de rastros”, de Camilo Pessanha. 1980. Dissertação (Mestrado em Letras - Literatura Portuguesa) - Faculdade de Filosofa, Letras e Ciências Humanas, Departamento de Letras Modernas, Universidade de São Paulo, São Paulo, 1980.

HUIZINGA, Johan. O outono da Idade Média. Tradução de Francis Petra Janssen. São Paulo: Cosac Naify, 2010.

JORGE, Luíza Neto. O sexo dos textos: traços da ficção narrativa de autoria feminina. In: MAGALHÃES, Isabel Allegro de Magalhães. O sexo dos textos e outras leituras. Lisboa: Editorial Caminho, 1995. p. 15-54.

LEITE, Ana Mafalda. Lee-Li Yang, um heterónimo feminino de Virgílio de Lemos. In: MATOS, Inocência. A mulher em África: vozes de uma margem sempre presente. Lisboa: Edições Colibri/Centro de Estudos Africanos, Faculdade de Letras da Universidade de Lisboa - FLUL, 2006. p. 381-390.

LEMOS, Virgílio de. Jogos de prazer. Virgílio de Lemos \& heterónimos: Bruno Reis, Duarte Galvão e Lee-Li Yang. Organização do volume e prefácio de Ana Mafalda Leite. Lisboa: Imprensa Nacional - Casa da Moeda, 2009.

LOPES, Elizabeth. A magia das máscaras: ator e seu duplo. In: BELTRAME, Valmor Níni; ANDRADE, Milton de (Org.). Teatro de Máscaras. Florianópolis: Universidade do Estado de Santa Catarina - UDESC, 2010.

MACHADO, Camila Toledo Piza. Lee-Li Yang: o espistolar em trnase poético. Rio de Janeiro, 2007. 107f. Disponível em: https://rive.google.com/file/d/1mp3k75dmCYiQpyVmIRR3cY04U5y7JCxb/view Acesso 04/05/2018.

VIEIRA, Yara Frateschi. Poesia medieval: literatura portuguesa. São Paulo: Global, 1987. 